\title{
KẾT QUẢ ĐIỀU TRI VẾT THƯƠNG TIM - CHẤN THƯƠNG TIM TẠI BỆNH VIỆN HŨ̉U NGH!̣ VIỆT TIỆP - HẢI PHÒNG
}

\author{
Nguyễn Thế May*, Nguyê̂n Công Huy*, Đỗ Đức Thắng*, \\ Đồng Minh Hùng*, Lê Minh Sơn*, Đoàn Quốc Hung **
}

\section{TÓM TÁT}

Mục tiêu: tổng kết kinh nghiệm chẩn đoán và điều trị 46 trường hợp vết thương, chấn thương tim tại bệnh viện hữu nghị Việt Tiệp Hải Phòng từ năm 2006 - 2015.

Phương pháp nghiên cứu: mô tả hồi cứu.

Kết quả: Từ 2006 tới 2015, có 46 bệnh nhân (40 nam) bị vết thương tim và chấn thương tim điều trị tại bệnh viện hữu nghị Việt Tiệp Hải Phòng, trong đó có 38 trường hợp $(82,61 \%)$ vết thương tim; 8 trường hợp chấn thương tim; độ tuổi bệnh nhân từ 15-80 (tuổi trung bình là $36,22 \pm 12,18) ; 28$ trường hợp $(60,87 \%)$ có hội chứng ép tim cấp; 12 trường hợp $(26,08 \%)$ có sốc mất máu; $32 / 38$ trường hợp $(84,21 \%)$ vết thương tim có vết thương ở vùng cảnh giác Peitzman. Thời gian trung bình từ khi bị thương đến khi vào viện là $65,35 \pm 35,38$ phút; có 29 trường hợp (63,04\%) được siêu âm tim trước mổ; tổn thương thất phải hay gặp nhất với 22 trường hợp $(47,82 \%)$; tỷ lệ tử vong là 15,22\% (7 trường hợp). Tù khóa: chấn thuơng tim, vết thuong tim.

SUMMARY: This paper discribes the results of 46 cases of penetrating cardiac injuries by stab wound and traumatic cardiac ruptures.

Method: Retrospective study, sectional description.

Results: During 10 years (2006-2015), there were 46 cases (40 males) of penetrating cardiac injuries and traumatic cardiac ruptures treated in Vietnam-Czech friendship hospital, Hai Phong city. There were 38 cases of penetrating cardiac injuries by stab wound; 8 cases of traumatic cardiac ruptures; the age of patients ranged from 15 to 80 (mean 36,22 $\pm 12,18$ ); 28 cases $(60,87 \%)$ with cardiac tamponade syndrom; 12 cases $(26,08 \%)$ with hypovolemic shock; $84,21 \%$ of cases of penetrating cardiac injuries with wound in cardiac Peitzman guard area. The interval between accident time and hospitalization time was about $65,35 \pm 35,38$ minutes; 29 cases $(63,04 \%)$ were performed echocardiography; common injuries were in right ventricle with 22 cases $(47,82 \%)$; mortality was $15,22 \%$ ( 7 cases).

Keyword: Cardiac trauma; cardiac wound

\section{1. ĐặT VẤN ĐỀ}

Vết thương tim-chấn thương tim là một cấp cứu ngoại khoa tối cấp, việc chẩn đoán và xử trí đòi hỏi phải được thực hiện nhanh chóng, chính xác và kịp thời để hạ thấp tối đa tỷ lệ tử vong. Hiện nay, với sự gia tăng của vết thương và chấn thương ngực, tỷ lệ vết thương tim và chấn thương tim có xu hướng tăng lên. Mặc dù y học đã có rất nhiều tiến bộ trong chẩn đoán, hồi sức, gây mê và phẫu thuật, nhưng tỷ lệ tử vong chung vẫn khoảng $5-50 \%$. Tuy nhiên, nếu bệnh nhân còn sống khi đến viện thì tỷ lệ sống sau mổ rất cao, có thể tới 80-90\%. Tại Bệnh viện hữu nghị Việt Tiệp Hải Phòng, trong 10 năm (2006-2015) chúng tôi đã phẫu thuật 46 trường hợp vết thương tim và chấn thương tim do chấn thương. Báo cáo này tổng kết các trường hợp đã được phẫu thuật vết thương tim-chấn thương tim tại bệnh viện hữu nghị Việt Tiệp.

\section{2. ĐỐI TƯợNG VÀ PHƯƠNG PHÁP NGHIÊN CỨU}

Đối tượng nghiên cứu: gồm các trường hợp chẩn đoán sau mổ vết thương - chấn thương tim được điều trị tại bệnh viện hữu nghị Việt Tiệp Hải Phòng từ năm 2006 đến 2015. Loại trừ những trường hợp chẩn đoán vết thương - chấn thương tim nhưng tử vong trước khi đến viện.

\section{Phương pháp nghiên cứu:}

- Mô tả hồi cứu

- Thu thập số liệu từ hồ sơ bệnh án

- Cỡ mẫu thuận tiện

- Xử lý số liệu bằng phần mềm SPSS 16.0

* * Bệnh viện hũu nghị Việt Tiệp Hải Phòng ** Bệnh viện Hũu Nghị Việt Đúc

Người chịu trách nhiệm khoa học: PGS.TS. Đoàn Quốc Hung

Ngày nhận bài: 10/01/2016 - Ngày Cho Phép Đăng: 24/02/2016

Phản Biện Khoa học: PGS.TS. Đặng Ngọc Hùng

GS.TS. Lề Ngọc Thành 


\section{KẾT QUẢ NGHIÊN CÚU:}

Từ năm 2006 - 2015 có 46 bệnh nhân đủ tiêu chuẩn nghiên cứu gồm 38 bệnh nhân vết thương tim và 8 bệnh nhân chấn thương tim với các đặc điểm như sau:

Bảng 1. Đặc điểm bệnh nhân theo độ tuổi $(N=46)$

\begin{tabular}{|l|c|c|}
\hline \multicolumn{1}{|c|}{ Độ tuổi } & Số bệnh nhân & Tỷ lệ \% \\
\hline Dưới 18 tuồi & 9 & 19,57 \\
\hline Từ $18-40$ tuổi & 25 & 54,35 \\
\hline Trên 40 tuối & 12 & 26,08 \\
\hline Tổng số & 46 & 100 \\
\hline
\end{tabular}

Độ tuổi trung bình là $36,22 \pm 12,18$; đa số từ 18 40 tuổi , nhỏ nhất là 15 tuổi, lớn nhất là 80 tuổi.

Bảng 2. Đặc điểm bệnh nhân theo giới $(N=46)$

\begin{tabular}{|l|c|c|}
\hline \multicolumn{1}{|c|}{ Giới } & Số bệnh nhân & Tỷ lệ \% \\
\hline Nam & 40 & 86,96 \\
\hline Nữ & 6 & 13,04 \\
\hline Tổng số & 46 & 100 \\
\hline
\end{tabular}

Bảng 3. Thời gian tù̀ khi bị thương cho đến khi vào viện

\begin{tabular}{|l|c|c|c|c|}
\hline $\begin{array}{c}\text { Thời gian } \\
\text { (giờ) }\end{array}$ & $\begin{array}{c}<\mathbf{1} \\
\text { giờ }\end{array}$ & $\begin{array}{c}\mathbf{1 - 2} \\
\text { giờ }\end{array}$ & $\begin{array}{c}>\mathbf{2} \\
\text { giờ }\end{array}$ & $\begin{array}{c}\text { Không xác } \\
\text { dịnh }\end{array}$ \\
\hline Số bệnh nhân & 31 & 4 & 5 & 6 \\
\hline Tỷ lẹ̣ \% & 67,39 & 8,69 & 10,87 & 13,05 \\
\hline
\end{tabular}

Bảng 4. Đặc điểm lâm sàng ( $N=46)$

\begin{tabular}{|l|l|c|c|}
\hline \multicolumn{2}{|c|}{ Dấu hiệu lâm sàng } & $\begin{array}{c}\text { Số bệnh } \\
\text { nhần }\end{array}$ & Tỷ lệ \% \\
\hline \multirow{3}{*}{ Tri giác } & Tỉnh & 38 & 82,61 \\
\cline { 2 - 4 } & $\begin{array}{l}\text { Vật vã }-100 \\
\text { mơ }\end{array}$ & 5 & 10,87 \\
\cline { 2 - 4 } & Mề & 3 & 6,52 \\
\hline \multirow{3}{*}{ Hô hấp } & Bình thường & 15 & 32,61 \\
\cline { 2 - 4 } & Thở nhanh & 26 & 56,52 \\
\cline { 2 - 4 } & Thở ngáp & 5 & 10,87 \\
\hline Có hội chứng ép tim & 28 & 60,87 \\
\hline \multicolumn{2}{|l|}{ Có sốc mất máu } & 12 & 26,08 \\
\hline
\end{tabular}

Bảng 5. Vị trí vết thuơng thành ngục theo vùng cảnh giác Peitzman (n=38)

\begin{tabular}{|c|c|c|}
\hline Vị trí vết thương & $\begin{array}{c}\text { Số bệnh } \\
\text { nhânn }\end{array}$ & Tỷ lệ \% \\
\hline Vùng cảnh giác Peitzman & 32 & 84,21 \\
\hline Ngoài vùng cảnh giác & 6 & 15,79 \\
\hline Tổng số & 38 & 100 \\
\hline
\end{tabular}

Bảng 6. Siêu âm tim trước mổ $(N=46)$

\begin{tabular}{|l|l|c|c|}
\hline \multicolumn{2}{|c|}{ Loại tổn thương } & $\begin{array}{c}\text { Số bệnh } \\
\text { nhân }\end{array}$ & $\begin{array}{c}\text { Tỷ lệ } \\
\text { \%o }\end{array}$ \\
\hline \multirow{2}{*}{$\begin{array}{l}\text { Vết thương } \\
\text { tim }\end{array}$} & Có siêu âm & 21 & 55,26 \\
\cline { 2 - 4 } & Không siêu âm & 17 & 44,74 \\
\hline \multirow{2}{*}{$\begin{array}{l}\text { Chấn thương } \\
\text { tim }\end{array}$} & Có siêu âm & 8 & 100 \\
\cline { 2 - 4 } & Không siêu âm & 0 & 0 \\
\hline \multicolumn{2}{|c|}{ Tổng số } & 46 & 100 \\
\hline
\end{tabular}

$100 \%$ bệnh nhân chấn thương tim đều được siêu âm tim trước mổ; có $21 / 38$ bệnh nhân vết thương tim được siêu âm tim trước mổ.

Bảng 7. Tổn thuơng giải phẫu tại tim ( $N=46)$

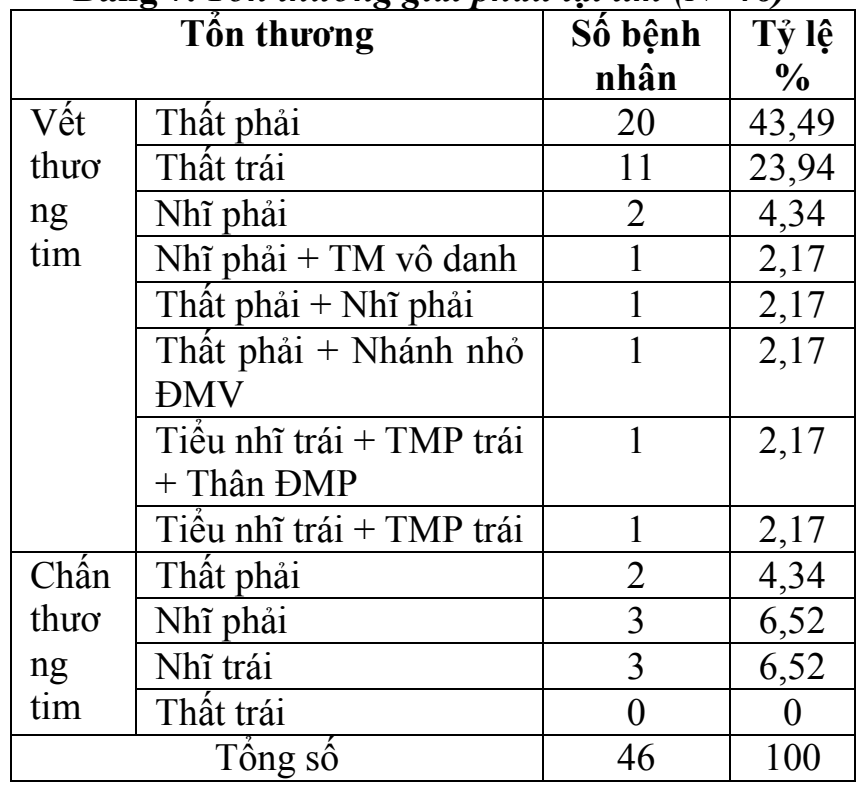

Bảng 8. Tổn thương phối hợp (N=46)

\begin{tabular}{|l|c|c|}
\hline \multicolumn{1}{|c|}{ Tổn thương } & $\begin{array}{c}\text { Số bệnh } \\
\text { nhân }\end{array}$ & Tỷ lệ \% \\
\hline Phổi: rách, thủng, dập nhu mô & 9 & 19,57 \\
\hline Động mạch phồi & 2 & 4,35 \\
\hline Tĩnh mạch phồi & 1 & 2,17 \\
\hline Động mạch ngực trong & 4 & 8,70 \\
\hline $\begin{array}{l}\text { Gãy/ đứt xương sườn, động } \\
\text { mạch liên sườn }\end{array}$ & 16 & 34,78 \\
\hline Vết thương khí quản & 1 & 2,17 \\
\hline Cơ hoành & 6 & 13,04 \\
\hline Gan & 2 & 4,35 \\
\hline Dạ dày & 1 & 2,17 \\
\hline Lách & 2 & 4,35 \\
\hline Dập nát chi thể & 1 & 2,17 \\
\hline
\end{tabular}


Bảng 9. Thời gian nằm viện (N=46)

\begin{tabular}{|l|c|c|}
\hline \multicolumn{1}{|c|}{ Thời gian nằm viện } & Số bệnh nhân & Tỷ lệ $\%$ \\
\hline Dưới 1 tuần & 8 & 17,39 \\
\hline Từ 1 tuần -2 tuần & 33 & 71,74 \\
\hline Trên 2 tuần & 5 & 10,87 \\
\hline
\end{tabular}

Bảng 10. Kết quả điều trị

\begin{tabular}{|l|c|c|}
\hline \multicolumn{1}{|c|}{ Kết quả } & Số bệnh nhân & Tỷ lệ \% \\
\hline Xuất viện ồn định & 39 & 84,78 \\
\hline Tử vong & 7 & 15,22 \\
\hline
\end{tabular}

\section{BÀN LUẬN}

\subsection{Về tuổi và giới}

Vết thương - chấn thương tim không phải là những tổn thương hiếm trong thực hành lâm sàng. Trong 10 năm qua (từ năm 2006 đến năm 2015) bệnh viện hữu nghị Việt Tiệp đã tiếp nhận và điều trị phẫu thuật cho 46 trường hợp vết thương tim và chấn thương tim. Đa số bệnh nhân là nam giới $(86,96 \%)$ và ở trong độ tuổi lao động 18 - 40 tuổi $(54,35 \%)$ (Bảng 1 và Bảng 2 ). Kết quả này cũng tương tự kết quả nghiên cứu của các tác giả khác như Lê Ngọc Thành (1999) [3], Phạm Minh Ánh (2007) [1], Campbell (1997) [7]. Nhiều tác giả trên thế giới khi nghiên cứu dịch tễ vết thương tim có đề cập đến vấn đề lạm dụng rượu, ma túy. Mặc dù ở Việt Nam chưa có nghiên cứu nào thông báo về vấn đề trên, nhưng có thể lý giải được là do nam giới, đặc biệt là ở độ tuổi lao động thường có xu hướng tham gia các hoạt động bạo lực và liên quan đến công việc lao động nặng nhiều hơn.

\subsection{Triệu chứng lâm sàng}

Trong 46 trường hợp có 10,87\% trường hợp trong tình trạng vật vã, lơ mo; $6,52 \%$ trường hợp trong tình trạng hôn mê; hầu hết bệnh nhân khi vào viện còn tỉnh $(82,61 \%) ; 10,87 \%$ trường hợp trong tình trạng thở ngáp, còn lại đa số bệnh nhân có nhịp thở nhanh nông (56,52\%); có 60,87\% trường hợp có hội chứng ép tim cấp; 26,08\% trường hợp có sốc mất máu (Bảng 4). Việc đánh giá và nhận định các dấu hiệu lâm sàng và tình trạng toàn thân của bệnh nhân khi đến viện có ý nghĩa quan trọng trong việc xác định thái độ xử trí và tiên lượng bệnh. Kết quả nghiên cứu này cũng phù hợp với nhận định của các tác giả trong và ngoài nước, cho rằng hội chứng ép tim cấp là thường gặp nhất trên lâm sàng và có giá trị chẩn đoán. Symbass (2002) [10] tổng kết 30 năm với 249 trường hợp thì $54 \%$ có hội chứng ép tim cấp, hay Phan Thanh Nam (2009) [2] nghiên cứu trên 73 trường hợp tại bệnh viện Việt Đức thì tỷ lệ này là $63 \%$. Một số tác giả cho rằng bản thân hội chứng ép tim cấp làm giảm mức độ mất máu và do đó bệnh nhân có thể "cầm cự" thêm một khoảng thời gian trước khi đến viện. Tuy nhiên khoảng thời gian "cầm cự" này là bao lâu thì vẫn chưa được xác định rõ ràng.

Vị trí đường vào của vết thương: Đối với vết thương tim do bạch khí thì vị trí vết thương thành ngực đóng vai trò quan trọng nhất trong chẩn đoán lâm sàng. Theo Harris, với tác nhân là bạch khí thì $60 \%$ có vết thương tim nếu vết thương thành ngực nằm ở vùng xung quanh xương ức hoặc trước tim [9]. Ngược lại, $85 \%$ bệnh nhân bị vết thương tim có vết thương thành ngực nằm ở vùng này [2]. Cách phân vùng cảnh giác theo Peitzman [2] tỏ ra hữu ích trong thực hành lâm sàng. Trong 38 trường hợp vết thương tim chúng tôi ghi nhận có 32 trường hợp $(84,21 \%)$ có vết thương nằm trong vùng cảnh giác Peitzman (vùng được giới hạn bởi: bên phải là đường giữa đòn phải, bên trái là đường nách trước trái, trên là đường ngang qua xương sườn II, dưới là đường ngang qua vùng thượng vị ở $1 / 3$ trên giữa rốn và mũi ức); 6 trường hợp khác có vết thương ở thành ngực bên và thành bụng, gây tổn thương phối hợp tạng trong ổ bụng. So sánh với các tác giả khác, cũng cho kết quả tương tự, như Phạm Minh Ánh (2007) [1], Asensio JA (1998) [6]. Điều này cho thấy áp dụng vùng cảnh giác Peitzman cho phép chúng ta chẩn đoán sớm và ít bỏ sót vết thương tim. Tuy nhiên cũng có những trường hợp vết thương không nằm trong vùng cảnh giác. Do vậy, 
không nên loại trừ vết thương tim ngay từ đầu khi thấy vết thương không nằm trong vùng cảnh giác Peitzman.

Thời gian từ khi bị thương đến khi nhập viện: Bệnh nhân được đưa đến viện sớm hay muộn rất quan trọng trong việc tiên lượng khả năng cấp cứu thành công hay không. Đa số các bệnh nhân trong nghiên cứu của chúng tôi đều đến viện trước 1 giờ (67,39\%) (Bảng 3), trong đó có 1 bệnh nhân được đưa đến sớm nhất là 25 phút sau khi bị vết thương. Tuy nhiên, còn có 6 trường hợp không xác định được chính xác khoảng thời gian bị thương trước khi đến viện.

\subsection{Siêu âm tim trước mổ}

Trong nghiên cứu của chúng tôi (Bảng 6), có $21 / 38$ trường hợp vết thương tim $(55,26 \%)$ được siêu âm tim trước mổ. Trong khi đó, tất cả 8 trường hợp chấn thương tim đều được siêu âm tim trước mổ. Kết quả $100 \%$ các trường hợp được siêu âm tim trước mổ đều phát hiện thấy dịch màng tim và được chẩn đoán có tổn thương tim. Có 17/38 trường hợp vết thương tim không kịp tiến hành siêu âm tim mà phải chuyển ngay vào mổ cấp cứu xử trí tổn thương do tình trạng bệnh nhân rất nặng. Siêu âm tim là thăm dò dễ thực hiện và rất có giá trị trong chẩn đoán vết thương tim và chấn thương tim mà không làm mất quá nhiều thời gian quý giá của người bệnh.

\subsection{Thương tổn giải phẫu bệnh}

-Đối với vết thương tim, vị trí tổn thương hay gặp nhất là ở thất phải. Trong đó, có 20 trường hợp vết thương thất phải đơn thuần $(43,49 \%)$ (Bảng 7), ngoài ra có 2 trường hợp vết thương thất phải kèm vết thương nhĩ phải và vết thương nhánh nhỏ động mạch vành. Nguyên nhân chủ yếu là do vị trí giải phẫu của thất phải nằm ngay ở mặt trước tim, nên thất phải dễ bị tổn thương do nguyên nhân bạch khí. Tổn thương đứng hàng thứ hai là vết thương ở thất trái với 11 trường hợp $(23,94 \%)$. Bên cạnh đó còn có 3 trường hợp vết thương nhĩ phải đơn thuần; 1 trường hợp vết thương phức tạp xuyên cả khí quản, động mạch phổi, tiểu nhĩ trái và tĩnh mạch phổi trái; 1 trường hợp xuyên tiểu nhĩ trái và tĩnh mạch phổi trái.

-Đối với 8 trường hợp vỡ tim, chúng tôi gặp 3 trường hợp vỡ nhĩ phải; 3 trường hợp vỡ nhĩ trái; 2 trường hợp vỡ thất phải; không có trường hợp nào vỡ thất trái. Đây là hậu quả từ những tác động lực mạnh vào vùng ngực, hay gặp trong các chấn thương do tai nạn giao thông, bên cạnh tổn thương vỡ tim thường kèm theo những tổn thương tạng và cơ quan khác.

-Bên cạnh những tổn thương giải phẫu tại tim, chúng tôi còn ghi nhận những tổn thương phối hợp ở ngoài tim (Bảng 8). Trong đó, tổn thương rách, thủng và đụng dập nhu mô phổi với 9 trường hợp (19,57\%); tổn thương gãy, đứt xương sườn, sụn sườn và động mạch vú trong có 16 trường hợp $(34,78 \%)$. Ngoài ra, chúng tôi ghi nhận những tổn thương phối hợp khác như: vết thương cơ hoành; vết thương dạ dày; vết thương gan, vỡ gan, vỡ lách; có 1 trường hợp dập nát chi dưới do chấn thương. Việc xử trí những tổn thương kèm theo có thể từ đơn giản đến phức tạp tùy theo loại tổn thương cụ thể. Vết thương động mạch ngực trong được khâu cầm máu. Vết thương nhu mô phổi được khâu lại. Tổn thương gan, lách và dạ dày được mở bụng để thám sát và xử lý khâu cầm máu. Những trường hợp có tổn thương kèm theo đã làm cuộc mổ trở nên phức tạp và kéo dài hơn rất nhiều. Điều đó làm cho tình trạng bệnh nhân vốn đã nặng lại càng nặng nề hơn. Chính vì vậy, đây cũng là một yếu tố góp phần vào tiên lượng cũng như kết quả điều trị trong nghiên cứu của chúng tôi.

\subsection{Kết quả điều trị (bảng 10)}

-Thời gian nằm viện: tất cả bệnh nhân còn sống trước khi ra viện đều được kiểm tra siêu âm tim, điện tim, chụp $x$-quang phổi và các xét nghiệm cơ bản 
khác. Trong nghiên cứu của chúng tôi, có 1 trường hợp nằm viện điều trị sau mổ ngắn nhất là 4 ngày; có 5 trường hợp điều trị trên 2 tuần, trong đó có 1 bệnh nhân điều trị 67 ngày do có nhiều tổn thương phối hợp và tình trạng diễn biến nặng trong và sau mổ; đa số bệnh nhân điều trị tại bệnh viện trong khoảng từ $1-2$ tuần $(71,74 \%)$. Điều này cũng cho thấy, nếu điều trị cấp cứu kịp thời thì quá trình điều trị diễn biến thuận lợi, tương tự như những trường hợp chấn thương và vết thương ngực thông thường.

- Tỷ lệ tử vong chung trong nghiên cứu của chúng tôi là $15,22 \%$ ( 7 trường hợp). Kết quả này theo chúng tôi là thuộc nhóm có tỷ lệ tử vong khá thấp, nhiều nghiên cứu trong và ngoài nước chỉ ra tỷ lệ tử vong từ trong khoảng từ $5-50 \%[8]$.

Khi phân tích nguyên nhân dẫn đến tử vong chúng tôi thấy rằng điều quan trọng nhất là tình trạng bệnh nhân khi vào viện và mức độ tổn thương trên tim cũng như những tổn thương phức tạp kèm theo. Trong 7 trường hợp tử vong thì tất cả đều có tình trạng huyết áp tụt, sốc mất máu khi vào viện. Trong đó, 3 trường hợp bị ngừng tim tại thời điểm vào viện được cấp cứu ngừng tuần hoàn, tim đập lại mới mổ, trong số này 1 trường hợp có vết thương tiểu nhĩ trái kèm với vết thương xuyên 2 mặt thân động mạch phổi và vết thương tĩnh mạch phổi trái trên, 1 trường hợp vết thương tiểu nhĩ trái và 2 tĩnh mạch phổi trái; 1 trường hợp có vết thương thất trái. Ngoài ra 1 trường hợp sốc mất máu nặng không hồi phục do vết thương hơn $3 \mathrm{~cm}$ ở thất phải; 1 trường hợp có đường vỡ mặt sau nhĩ trái dài $2,5 \mathrm{~cm}$ giữa chỗ đổ về của 4 tĩnh mạch phổi, mặc dù phẫu thuật khâu được tổn thương nhưng tình trạng bệnh nhân trong mổ diễn biến nặng, có đợt ngừng tim và đã tử vong vào ngày thứ 2 sau mổ do tình trạng tổn thương quá nặng kèm tắc mạch khí; 1 trường hợp tử vong vì sốc mất máu nặng do tổn thương nhĩ phải kèm theo đứt gần rời tĩnh mạch vô danh; 1 trường hợp tử vong do tổn thương nặng phối hợp vỡ thất phải kèm theo vỡ gan và lách trong đa chấn thương.

\section{KẾT LUẬN}

Qua 46 trường hợp vết thương tim-chấn thương tim được chẩn đoán và điều trị phẫu thuật tại bệnh viện hữu nghị Việt Tiệp Hải Phòng giai đoạn 20062015, chúng tôi rút ra một số kết luận như sau:

-Bệnh nhân chủ yếu là nam giới $(86,96 \%)$ và nằm trong độ tuổi lao động 18 - 40 tuổi $(54,35 \%)$. Đa số bệnh nhân có vết thương ở vùng cảnh giác Peitzman $(84,21 \%)$

-Siêu âm tim: rất có giá trị chẩn đoán trong cấp cứu vết thương và vỡ tim do chấn thương.

-Tổn thương hay gặp nhất là thất phải $(43,49 \%)$; tiếp theo là tổn thương thất trái $(23,94 \%)$. Tỷ lệ tử vong chung trong và sau mổ là $15,22 \%$; xảy ra ở những bệnh nhân sốc mất máu không hồi phục, tổn thương phức tạp ở tim cũng như tổn thương phối hợp ngoài tim, đặc biệt những tổn thương phức tạp ở nhĩ trái và tĩnh mạch phổi.

\section{TÀI LIỆU THAM KHẢO}

1. Phạm Minh Ánh (2007). Nghiên cưu các dấu hiệu lâm sàng và cận lâm sàng trong chẩn đoán vêt thuoong tim tại bệnh viện Việt Tiệp - Hải Phòng, Luận án tiến sỹ Y học, Học viện Quân Y.

2. Phan Thanh Nam (2009). Đánh giá kết quả chẩn đoán và điều trị vết thuoong tim tại Bệnh viện hũu nghị Việt Đúc, Luận văn thạc sỹ Y học, Đại học Y Hà Nội.

3.Lê Ngọc Thành, Đặng Hanh Sơn (1999). “Thông báo lâm sàng vết thương tim tại bệnh viện Việt Đức 1990 - 1996", Ngoại khoa, 1(34):1-7. 
4. Trần Quyết Tiến (2001). Một vài nhận xét về tử vong trong cấp cứu vết thương và chấn thương tim tại bệnh viện Chợ Rẫy từ 1/1987 đến 6/2000, Tạp chi Y học Thành phố Hồ Chí Minh, Tập 5, Số 1.

5. Nguyễn Hữu Ước (2001). Các đường mở ngực trong cấp cứu, Phẫu thuật cấp cưu tim mạch và lồng ngục, NXB Y Học, Hà Nội, 53 - 68.

6. Asensio JA, Berne JD, Demetriades D, Chan L et al (1998). One hundred five penetrating cardiac injuries: a 2-year evaluation, J Trauma, 44(6): 1073 - 82.

7. Campbell NC, Thomson SR, Muckart DJ et al (1997). Review of 1198 cases of penetrating cardiac trauma, Br J Surg, 84(12): $1737-40$.
8. Edward H. Kincaid, J. Wayne Meredith (2008). Cardiac Injuries. Trauma: Contemporary Principles and Therapy 1st Edition, Lippincott Williams \& Wilkins: p. 379-382

9. Harris DG, Papagiannopoulos KA, Pretorius J, Van Rooven T, Rossouw GJ (1999). Current evaluation of cardiac stab wounds, Ann Thorac Surg, 68(6): $2119-22$.

10. Symbas PN,(2002). Penetrating cardiac wounds: Evolution of diagnosis, treatment, and results over a 30 year period, Hellenic Medicine, 19(3): 301-304 